Author affiliations and support information (if applicable) appear at the end of this article.

Published at jco.org on March 13, 2017. Clinical trial information: NCT02209857. Corresponding author: Thijs van Dalen, $\mathrm{PhD}$, Department of Surgery, Diakonessenhuis, Bosboomstraat 1, Utrecht, $3582 \mathrm{KE}$, the Netherlands; e-mail: tvdalen@diakhuis.nl.

C 2017 by American Society of Clinical Oncology

0732-183X/17/3599-1/\$20.00

\title{
Impact of 70-Gene Signature Use on Adjuvant Chemotherapy Decisions in Patients With Estrogen Receptor-Positive Early Breast Cancer: Results of a Prospective Cohort Study
}

Anne Kuijer, Marieke Straver, Bianca den Dekker, Annelotte C.M. van Bommel, Sjoerd G. Elias, Carolien H. Smorenburg, Jelle Wesseling, Sabine C. Linn, Emiel J.Th. Rutgers, Sabine Siesling, and Thijs van Dalen

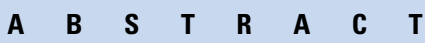

\section{Purpose}

Gene-expression profiles increasingly are used in addition to conventional prognostic factors to guide adjuvant chemotherapy (CT) decisions. The Dutch guideline suggests use of validated geneexpression profiles in patients with estrogen receptor (ER) -positive, early-stage breast cancer without overt lymph node metastases. We aimed to assess the impact of a 70-gene signature (70-GS) test on CT decisions in patients with ER-positive, early-stage breast cancer.

\section{Patients and Methods}

In a prospective, observational, multicenter study in patients younger than 70 years old who had undergone surgery for ER-positive, early-stage breast cancer, physicians were asked whether they intended to administer adjuvant CT before deployment of the 70-GS test and after the test result was available.

\section{Results}

Between October 1, 2013, and December 31, 2015, 660 patients, treated in 33 hospitals, were enrolled. Fifty-one percent of patients had pT1cN0, BRII, HER2-Neu-negative breast cancer. On the basis of conventional clinicopathological characteristics, physicians recommended CT in 270 (41\%) of the 660 patients and recommended withholding CT in 107 (16\%) of the 660 patients. For the remaining $43 \%$ of patients, the physicians were unsure and unable to give advice before $70-\mathrm{GS}$ testing. In patients for whom CT was initially recommended or not recommended, 56\% and 59\%, respectively, were assigned to a low-risk profile by the $70-\mathrm{GS}(\kappa, 0.02 ; 95 \% \mathrm{Cl},-0.08$ to 0.11$)$. After disclosure of the $70-\mathrm{GS}$ test result, the preliminary advice was changed in $51 \%$ of patients who received a recommendation before testing; the definitive CT recommendation of the physician was in line with the $70-\mathrm{GS}$ result in $96 \%$ of patients.

\section{Conclusion}

In this prospective, multicenter study in a selection of patients with ER-positive, early-stage breast cancer, 70-GS use changed the physician-intended recommendation to administer CT in half of the patients.

\section{J Clin Oncol 35. (c) 2017 by American Society of Clinical Oncology}

\section{INTRODUCTION}

During the past two decades, treatment guidelines for adjuvant systemic therapy in breast cancer have changed considerably; today, chemotherapy (CT) is advised in the majority of patients. The recommendation to administer adjuvant CT is based on clinicopathological prognostic factors. There is growing awareness that conventional factors do not accurately estimate the prognosis or the benefit of CT in patients with estrogen receptor (ER) -positive breast cancer, which is reflected by a more reticent attitude toward CT administration in these patients in recent treatment guidelines. ${ }^{1}$

Several gene-expression profiles, such as the 70-gene signature (70-GS; MammaPrint, Agendia, Amsterdam, Netherlands), have been developed to aid adjuvant CT decision making in ER-positive, early-stage breast cancer. ${ }^{2,3}$ The 70-GS was validated in several retrospective studies ${ }^{4-9}$ and in a community-based feasibility study. ${ }^{10,11}$

Recently, the results of the MINDACT (microarray in node negative disease may avoid CT) trial provided the first level-1A evidence that 
omission of CT in patients assigned to the 70-GS low-risk category is safe. ${ }^{12}$ While the results of randomized clinical trials that compare the value of gene-expression profiles to clinicopathological factors when adjuvant chemotherapy is considered were awaited, national ${ }^{13}$ and international ${ }^{1,14}$ guidelines advised the use of a gene-expression profile in a selection of patients with earlystage ER-positive disease. The Dutch guideline has recommended use of a validated gene-expression profile since 2012 for patients with ER-positive invasive ductal carcinoma in whom doubt exists about CT benefit on the basis of clinicopathological factors. ${ }^{13}$ This guideline considers CT beneficial in patients who have an expected 10 -year breast cancer-specific mortality of at least $15 \%$, because these patients would have an absolute overall survival gain of $4 \%$ to $5 \%$ as a result of adjuvant CT administration. In common practice, gene-expression profiles in the Netherlands until now have been used mainly in patients with ER-positive, HER2-Neu-negative disease without overt lymph node metastases (pT1c-2N0-1mi). ${ }^{15}$ In the Netherlands, the 70-GS test accounts for $97 \%$ of all deployed gene-expression tests. ${ }^{16}$

The aim of this prospective, observational, multicenter study was to assess the impact of the 70-GS test on individual physician decisions when there was doubt about the benefit of adjuvant CT in patients with surgically treated, ER-positive, early-stage breast cancer.

\section{PATIENTS AND METHODS}

\section{Study Design}

This study was an observational, prospective, multicenter study to assess the impact of 70-GS test use on adjuvant CT decision making. Patients for whom 70-GS test deployment was considered as part of routine clinical practice were eligible for participation. The Dutch national guideline suggests deployment of a validated gene-expression profile for patients with ER-positive ductal carcinomas in whom doubt exists about CT benefit. This guideline also states that, for patients with an expected 10year overall survival of $85 \%$ or less, CT is indicated. It was expected that gene-expression profiles would be deployed only in patients with ERpositive, HER2-negative, low- or intermediate-grade tumors of stage T1c$2 \mathrm{~N} 0-1 \mathrm{mi}^{15}$

Patients treated between January 1, 2013, and December 31, 2015, in 33 participating hospitals were enrolled after they provided informed consent before deployment of the 70-GS test. Exclusion criteria were a history of malignancy, distant metastasis, and neoadjuvant systemic treatment. The study was approved by the medical ethics committee of the University Medical Center Utrecht (12-450) and by institutional review boards of participating centers. The study protocol (protocol number 12-450) was registered in the clinicaltrial.gov database (NCT02209857).

Eligible patients were identified during postoperative multidisciplinary team meetings, in which a preliminary CT recommendation was formulated on the basis of the clinicopathological results (Fig 1). The treating physician completed the first clinical report form (CRF1), in which information on clinicopathological characteristics and the preliminary CT recommendation - to administer $\mathrm{CT}$, withhold adjuvant $\mathrm{CT}$, or state uncertainty and give no advice-were registered. The estimated 10-year overall survival without CT, which was based on the PREDICT tool from the United Kingdom National Health Service, ${ }^{17}$ was calculated for every patient to objectify the prognostic perspective of the preliminary CT recommendation. Unlike the Adjuvant! Online tool, PREDICT incorporates HER2 status in its model. ${ }^{18}$

After completion of CRF1, the tumor samples were sent for 70-GS analysis, and the results were disclosed to the oncologist within 10 working

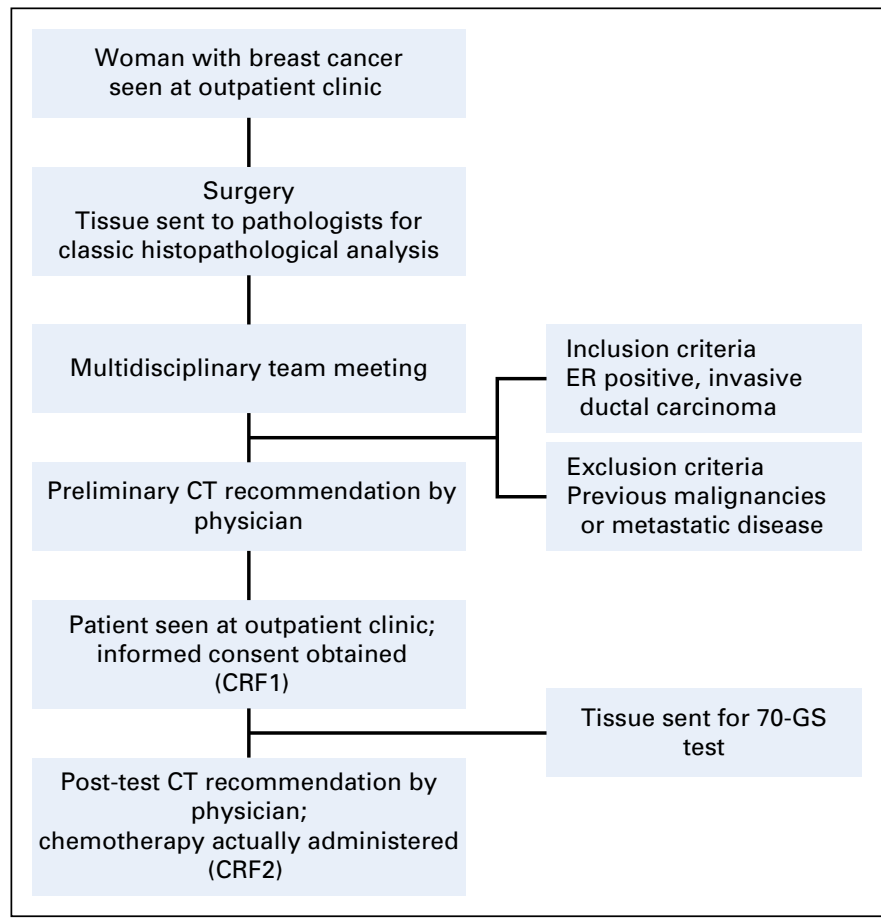

Fig 1. Flowchart of study inclusion between October 2013 and January 2016. CRF1, first clinical report form; CRF2, second clinical report form; CT, chemotherapy; ER, estrogen receptor; GS, gene signature.

days. The posttest CT recommendation and the actually administered CT were recorded in a second CRF (CRF2).

\section{End Points}

The primary end point was the percentage of patients for whom 70-GS use led to an altered adjuvant CT recommendation. A secondary end point was the relationship between the preliminary recommendation by the physician and the proportion of patients who actually received CT. Both outcomes also were calculated by basing the recommendation of adjuvant $\mathrm{CT}$ on the estimated 10 -year overall survival of $85 \%$ as a surrogate cutoff value, because the national guideline considers an estimated 10-year survival of less than $85 \%$ as a reason to recommend CT.

\section{Statistical Analysis}

Demographic and clinical characteristics of all patients were summarized in a baseline table. The differences in estimated median 10-year overall survival and CT benefit in relation to the recommendation before deployment of the test and in relation to the test result were compared with the Kruskall-Wallis test and the Mann-Whitney $U$ test, respectively. The percentage of changes in CT recommendation was assessed with the McNemar test. Agreement between the preliminary CT recommendation and the 70-GS test result was assessed with the Cohen $\kappa$ statistic, which can be interpreted as follows: values of 0 or lower indicate no agreement; of 0.01 to 0.20 , no to slight agreement; of 0.21 to 0.40 , fair agreement; of 0.41 to 0.60 , moderate agreement; of 0.61 to 0.80 , substantial agreement; and of 0.81 to 1.00 , almost perfect agreement. All analyses were performed in $\mathrm{R}$ version 3.1.3.

\section{RESULTS}

A total of 698 patients with ER-positive, early-stage breast cancer were enrolled, and the mean number of patients per participating 
hospital was 21 (range, 2 to 60 patients). Thirty-eight patients were excluded from the study because of the following: no written informed consent $(n=5)$ and incomplete data on either the preliminary or the posttest CT recommendation at the closing date of the study $(\mathrm{n}=33)$. A total of 660 patients (median age, 57 years) had evaluable data. The prevailing group was composed of postmenopausal women who had unifocal HER2-negative, lowgrade tumors greater than $2 \mathrm{~cm}$ or intermediate-grade tumors of 1 to $2 \mathrm{~cm}$ without axillary lymph node involvement ( $\mathrm{pN} 0$ or $\mathrm{pN} 1 \mathrm{mi}$; $\mathrm{n}=405)$. On the basis of clinicopathological characteristics, the median estimated overall 10-year survival according to PREDICT was $86.1 \%$ (range, $40.2 \%$ to $95.3 \%$; interquartile range [IQR], $7.4 \%$ ), and the expected CT benefit was $1.6 \%$ (range, $0.4 \%$ to $8.5 \%$; IQR, $1.0 \%)$.

Before deployment of the 70-GS test, oncologists recommended CT in $41 \%$ and advised against it in $16 \%$ of patients. In the remaining $43 \%$ of patients, no preliminary CT recommendation was made, because physicians preferred to await the 70-GS test result (Fig 2). Patients to whom CT was recommended were younger and had larger tumors of higher grades than patients into whom physicians advised against adjuvant CT or patients to whom oncologists gave no advice (Table 1). There was no significant difference in median 10-year overall survival according to PREDICT among the three pretest CT recommendation groups $(P=.231)$.

The 70 -GS test assigned $41 \%$ of all patients to the high-risk category. Of patients to whom CT was initially advised, 56\% were assigned to the low-risk category by the 70-GS compared with 59\% of the patients to whom CT was not recommended. The preliminary advice was in line with the 70-GS risk category in $48 \%$ of patients. There was no to slight agreement between this preliminary CT advice and the $70-\mathrm{GS}$ test result $(\kappa, 0.02 ; 95 \%$ CI, -0.08 to $0.11 ; P=0.342$; Fig 2).

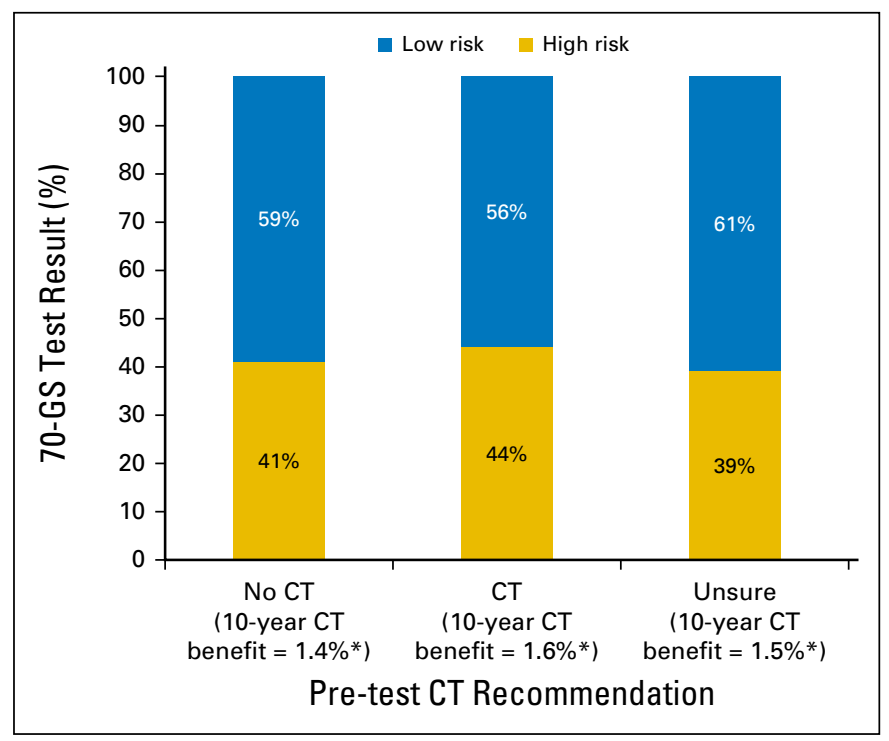

Fig 2. Concordance between pretest chemotherapy (CT) recommendation of the oncologist and the 70-gene signature (GS) test result. Agreement between pretest oncologist CT recommendation and the 70-GS test result: Cohen's к, 0.02 ; $95 \% \mathrm{Cl},-0.08$ to $0.11 ; P=0.3415)$. ( $\left.{ }^{*}\right)$ Median estimated 10 -year benefit of adjuvant CT on the basis of the UK-PREDICT tool per pretest CT recommendation category.
A subgroup analysis in patients with tumors greater than $2 \mathrm{~cm}$ $(\mathrm{n}=146)$ or in patients with axillary lymph node involvement ( $\mathrm{pN} 1 \mathrm{mi}$ or worse stage; $\mathrm{n}=103$ ) yielded similar proportions of patients assigned to the risk categories; discordance between the preliminary CT advice and the 70-GS test result occurred in 56\% ( $\kappa,-0.04 ; 95 \% \mathrm{CI},-0.24$ to 0.17$)$ and $62 \%(\kappa-0.10 ; 95 \% \mathrm{CI}$, -0.33 to 0.13 ) of patients, respectively.

The oncologist adhered to the 70-GS test result in $96 \%$ of patients: in 18 patients in the 70-GS low-risk category, oncologists recommended CT; in nine patients in the 70-GS high-risk category, oncologists advised against CT. Actually administered CT was the same as the posttest recommendations by oncologists in $94 \%$ of patients. Thirty patients to whom CT was recommended, of which 29 had a high-risk 70-GS test result, did not receive CT. Conversely, eight patients received CT despite the advice of the oncologists to withhold CT; seven of these patients had a low-risk 70-GS test result. Eventually administered CT was in line with the 70-GS test result in $91 \%$ of patients.

The recommendation was changed after 70-GS test use in 51\% (95\% CI, $46 \%$ to $56 \% ; P<.001$; Table 2) of patients for whom the clinician formulated a clear recommendation prior to the test $(\mathrm{n}=377)$. Actually administered CT deviated from the preliminary CT recommendation in $52 \%$ of the patients.

By using the 10 -year estimated survival of $85 \%$ as the cutoff value to administer CT or not, CT would have been considered beneficial in 289 patients $(44 \%)$. In $37 \%$ of patients $(n=139)$ who had estimated 10 -year survival rates greater than $85 \%$, the $70-\mathrm{GS}$ test indicated a high-risk result; in $46 \%$ of patients $(n=132)$ who had estimated 10-year survival rates less than $85 \%$, the 70 -GS test indicated a high-risk result. Again, no or only slight agreement between the 10-year survival categories and the 70-GS test results was observed ( $\kappa, 0.08 ; 95 \% \mathrm{CI}, 0.01$ to 0.16 ). A recommendation that was based on the estimated 10-year survival did not correspond to the 70-GS test result in almost half of the patients (45\%; $95 \%$ CI, $41 \%$ to $49 \%$ ). The physician adhered to the $70-\mathrm{GS}$ test result in $96 \%(n=357)$ and $96 \%(n=276)$ of patients who had an estimated 10 -year survival of greater than $85 \%$ or less than $85 \%$, respectively.

\section{DISCUSSION}

The results of this prospective, multicenter study demonstrated that 70-GS test use has substantial impact on CT decision making in patients with early-stage, ER-positive, HER2-negative breast cancer: 70-GS test use changed the premeditated advice from oncologists about adjuvant CT treatment in half of the patients. In addition, physicians were uncertain and unable to give advice without the 70-GS test in a substantial proportion of patients.

In this study, 70-GS test use led to altered advice about whether to administer CT or not in $51 \%$ of patients, and CT was administered in contradiction with the preliminary recommendation in a similar proportion of patients. Adherence of physicians and patients to the 70-GS test result was high and in line with recent studies. ${ }^{19,20}$ In studies in which multidisciplinary teams formulated advice before and after deployment of the 70-GS test, CT recommendation changes ranged from $16 \%$ to $38 \% .^{20-23}$ Similar results about the impact of Oncotype DX (Genomic 


\begin{tabular}{|c|c|c|c|c|}
\hline \multirow[b]{2}{*}{ Characteristic } & \multirow[b]{2}{*}{ All Patients $(N=660)$} & \multicolumn{3}{|c|}{ Pretest CT Advice } \\
\hline & & Yes $(n=270)$ & No $(n=107)$ & No Advice Given $(n=283)$ \\
\hline \multicolumn{5}{|l|}{ Patient characteristic } \\
\hline Mean (SD) age, years & $57.0(8.1)$ & $56.2(7.9)$ & $58.5(8.0)$ & $57.2(8.3)$ \\
\hline \multicolumn{5}{|l|}{ Menopausal status } \\
\hline Pre- or perimenopausal & 218 (34) & 102 (39) & $28(27)$ & $88(32)$ \\
\hline Postmenopausal & $428(66)$ & $162(61)$ & 76 (73) & $190(68)$ \\
\hline Missing & 14 & 6 & 3 & 5 \\
\hline \multicolumn{5}{|l|}{ Tumor characteristic } \\
\hline Unifocal disease & $596(90)$ & $250(93)$ & $97(91)$ & $249(88)$ \\
\hline \multicolumn{5}{|l|}{ Invasive tumor grade } \\
\hline 1 & $96(15)$ & $29(11)$ & $25(23)$ & $42(15)$ \\
\hline 2 & $481(73)$ & $195(72)$ & $77(72)$ & $209(74)$ \\
\hline 3 & $82(12)$ & $46(17)$ & $5(5)$ & $31(11)$ \\
\hline Mean (SD) tumor size, $\mathrm{mm}^{*}$ & $16.4(7.0)$ & $16.9(5.7)$ & $16.1(12.0)$ & $16.2(5.3)$ \\
\hline pT1 & $534(81)$ & $212(79)$ & $96(90)$ & $226(80)$ \\
\hline pT2 & $125(19)$ & $58(22)$ & $10(9)$ & $57(20)$ \\
\hline pT3 & $1(0)$ & - & $1(1)$ & - \\
\hline PR-positive disease & $571(87)$ & $231(86)$ & $90(84)$ & $250(88)$ \\
\hline HER2-negative disease & $638(97)$ & $259(96)$ & $105(98)$ & $274(97)$ \\
\hline \multicolumn{5}{|l|}{ Axillary lymph node involvement $\dagger$} \\
\hline pNo & $552(84)$ & $224(83)$ & $95(89)$ & $233(82)$ \\
\hline pN1mi & $65(10)$ & $27(10)$ & $5(5)$ & $33(12)$ \\
\hline pN1a & $35(5)$ & $17(6)$ & $6(6)$ & $12(4)$ \\
\hline$>$ pN1a & $3(1)$ & - & - & $3(1)$ \\
\hline$N x$ & $5(1)$ & $2(1)$ & $1(1)$ & $2(1)$ \\
\hline \multicolumn{5}{|l|}{ Treatment characteristic } \\
\hline \multicolumn{5}{|l|}{ Surgery } \\
\hline Breast-conserving surgery & $532(81)$ & $211(78)$ & $91(85)$ & $230(81)$ \\
\hline Mastectomy & $128(19)$ & $59(22)$ & $16(15)$ & 53 (19) \\
\hline \multicolumn{5}{|l|}{ Axillary surgery } \\
\hline SNP & $621(94)$ & $258(96)$ & $96(90)$ & 267 (94) \\
\hline ALND & $6(2)$ & $1(0)$ & $4(4)$ & $1(0)$ \\
\hline
\end{tabular}

Health, Redwood City, CA) and Prosigna (Nanostring Technologies, Seattle, WA) use have been reported. A recent meta-analysis was conducted to assess the impact of Oncotype DX on adjuvant CT decisions; the results demonstrated a change in CT decisions in
$38 \%$ of recommendations to patients with early-stage, ER-positive, HER2-negative breast cancer $^{24}$ Two prospective, multicenter studies addressed the influence of Prosigna use on CT decision making and reported an impact on CT decisions in $18 \%$ and $20 \%$

\begin{tabular}{|c|c|c|c|c|c|c|c|}
\hline \multirow{2}{*}{$\begin{array}{c}\text { Preliminary } \\
\text { Recommendation }\end{array}$} & \multirow[b]{2}{*}{ No. of Patients } & \multicolumn{2}{|c|}{$\begin{array}{c}\text { Posttest } \\
\text { Recommendation, } \\
\text { No. (\%) }\end{array}$} & \multirow{2}{*}{$\begin{array}{c}\text { Adherence to } \\
\text { Test Result }(\%)^{*}\end{array}$} & \multicolumn{2}{|c|}{$\begin{array}{l}\text { Actual Administration } \\
\text { of CT, No. (\%) } \\
\end{array}$} & \multirow[b]{2}{*}{ Adherence to Test Result $(\%)^{*}$} \\
\hline & & No CT & CT & & No & Yes & \\
\hline No CT & 107 & $69(65)$ & $38(35)$ & 94 & $73(68)$ & $34(32)$ & 91 \\
\hline $\mathrm{CT}$ & 270 & $156(58)$ & $114(42)$ & 97 & $162(60)$ & $108(40)$ & 90 \\
\hline Unsure & 283 & $173(61)$ & $110(39)$ & 95 & $185(65)$ & 98 (35) & 91 \\
\hline \multicolumn{8}{|c|}{$\begin{array}{l}\text { NOTE. There was in change in CT recommendation in } 51 \%(95 \% \mathrm{Cl}, 46 \% \text { to } 56 \% ; P<.001) \text { of patients who had a clear pretest CT recommendation (ie, yes or no CT; } \\
\mathrm{n}=377) \text {. Actually administered CT differed from the preliminary CT recommendation in } 52 \%(95 \% \mathrm{Cl}, 0.47 \% \text { to } 0.57 \% \text {; } P<.001) \text { of patients who had a clear pretest } \\
\mathrm{CT} \text { recommendation. } \\
\text { Abbreviations: } \mathrm{CT} \text {, chemotherapy; GS, gene signature. } \\
\text { *Percentage of patients in whom the posttest recommendation/actually administered CT was in line with the } 70-\mathrm{GS} \text { test result (ie, no CT in patients with a low-risk } \\
\text { profile and CT in patients with a high-risk profile). }\end{array}$} \\
\hline
\end{tabular}


of patients, respectively. ${ }^{25,26}$ Unlike these two prospective studies, the oncologist could refrain from giving an advice before deployment of the 70-GS test in this study, which might have led to overestimation of the proportion of patients in whom the treatment advice was changed. In another large, prospective study to assess the impact of Oncotype DX use on CT decision making in patients with early-stage, ER-positive, HER2-negative breast cancer, the option to refrain from giving advice before deployment of a gene-expression test was available for participating physicians. This study reported a CT recommendation change in $50 \%$ of patients after Oncotype DX use, which is in concordance with our results. $^{27}$

In addition, an estimated 10-year overall survival of $85 \%$, retrospectively estimated by PREDICT, was applied to the study group as a cutoff value to determine whether to administer adjuvant CT. Even when this cutoff value was used, the 70-GS test result differed from the surrogate recommendation that was based on PREDICT in almost half of the patients.

In this study, the oncologist recommended administration of adjuvant CT to $41 \%$ of all patients before $70-\mathrm{GS}$ testing. This is in line with data from a nationwide study conducted by our research group, which used observational Netherlands Cancer Registry data: $45 \%$ of all Dutch patients with (pT1-2N0mi) ER-positive, HER2negative breast cancer for whom no 70-GS test was deployed received adjuvant $\mathrm{CT} .{ }^{15}$ This illustrates the current controversy about CT benefit in this specific patient population.

To our knowledge, this is the largest prospective study to date to evaluate the impact of 70-GS test use on CT decision making, and the design of this study mimics routine clinic practice. Nevertheless, the pretest CT recommendation by the oncologists remains an artificial statement made with the prospect of an obtained 70-GS test result. In addition, because of the observational design of the study, it is possible that oncologists used the 70-GS test only in a selection of eligible patients, which would result in an overestimation of adherence rates or percentages of treatment change. Despite these limitations, the impact of 70-GS test use on CT decision making in patients with ER-positive, HER2-negative disease was substantial.

The impact of the 70-GS test on CT decision making was assessed in patients with ER-positive, HER2-negative disease for whom controversy about CT benefit led to use of the 70-GS test. ${ }^{4-10}$ It is important to note that, in this study, the prognostic value of the 70-GS test was used to guide CT decisions. Future studies have to be conducted to provide outcome data that support the altered decisions. For that purpose, we intend to merge the data of this study with the Netherlands Cancer Registry database. Also, robust results of the recently presented European Organisation for the Research and Treatment of Cancer (EORTC) 10041/BIG 03-04 MINDACT trial indicate that $46 \%$ of patients with breast cancer who are identified as high risk for recurrence according to clinicopathological factors are assigned to the 70-GS low-risk category. These patients are unlikely to derive significant benefit from CT. ${ }^{12}$ The indication area for 70-GS test use, as stated in the current clinical guidelines, will likely extend to the clinical higher-risk categories of patients. This study demonstrates that the 70-GS test is supportive for CT decision making in assumed high-risk populations, such as patients wo have larger tumors or lymph node metastases. At the same time, the MINDACT trial also indicates that, in patients identified as having a low risk of recurrence according to clinicopathological factors who are assigned to the 70-GS high-risk category, there is no significant difference in the 5 -year distant metastasis-free survival between the patients who received adjuvant CT and those who did not receive CT. This suggests no clinical utility of the 70-GS test in patients with low clinical risks, and this may lead to less use of the 70-GS test in these patients.

In this study in patients with ER-positive, HER2-negative, low- or intermediate-grade, breast cancer of stage T1c-2N0-1mi, 70-GS test use changed the physician-intended recommendation to administer CT in half of the patients. The weak correlation between the pretest CT recommendation and the 70-GS result implies that oncologists encounter difficulties in the recommendation about whether to administer CT without use of a geneexpression profile in this group of patients. Although previous studies have demonstrated the existing controversy about the use of CT in this group of patients, this study demonstrates the inability of physicians to make an accurate chemotherapy recommendation on the basis of conventional prognostic factors alone.

\section{AUTHORS' DISCLOSURES OF POTENTIAL CONFLICTS} OF INTEREST

Disclosures provided by the authors are available with this article at jco.org.

\section{AUTHOR CONTRIBUTIONS}

Conception and design: Anne Kuijer, Marieke Straver, Annelotte C.M. van Bommel, Sjoerd G. Elias, Carolien H. Smorenburg, Emiel J.Th. Rutgers, Sabine Siesling, Thijs van Dalen

Collection and assembly of data: Anne Kuijer, Jelle Wesseling, Thijs van Dalen

Data analysis and interpretation: Anne Kuijer, Marieke Straver, Bianca den Dekker, Sjoerd G. Elias, Sabine C. Linn, Sabine Siesling, Thijs van Dalen

Manuscript writing: All authors

Final approval of manuscript: All authors

Accountable for all aspects of the work: All authors

\section{REFERENCES}

1. Goldhirsch A, Wood WC, Coates AS, et al: Strategies for subtypes: Dealing with the diversity of breast cancer-Highlights of the St Gallen International Expert Consensus on the Primary Therapy of Early Breast Cancer 2011. Ann Oncol 22:1736-1747, 2011
2. van 't Veer LJ, Dai H, van de Vijver MJ, et al: Gene expression profiling predicts clinical outcome of breast cancer. Nature 415:530-536, 2002

3. van de Vijver MJ, He YD, van't Veer LJ, et al: A gene-expression signature as a predictor of survival in breast cancer. N Engl J Med 347:1999-2009, 2002

4. Buyse M, Loi S, van't Veer L, et al: Validation and clinical utility of a 70-gene prognostic signature for women with node-negative breast cancer. J Natl Cancer Inst 98:1183-1192, 2006

5. Bueno-de-Mesquita JM, Linn SC, Keijzer R, et al: Validation of 70-gene prognosis signature in node-negative breast cancer. Breast Cancer Res Treat 117:483-495, 2009

6. Mook S, Schmidt MK, Viale G, et al: The 70-gene prognosis-signature predicts disease outcome 
in breast cancer patients with 1-3 positive lymph nodes in an independent validation study. Breast Cancer Res Treat 116:295-302, 2009

7. Knauer M, Mook S, Rutgers EJ, et al: The predictive value of the 70-gene signature for adjuvant chemotherapy in early breast cancer. Breast Cancer Res Treat 120:655-661, 2010

8. Mook S, Schmidt MK, Weigelt B, et al: The 70gene prognosis signature predicts early metastasis in breast cancer patients between 55 and 70 years of age. Ann Oncol 21:717-722, 2010

9. Mook S, Knauer M, Bueno-de-Mesquita JM, et al: Metastatic potential of T1 breast cancer can be predicted by the 70-gene MammaPrint signature. Ann Surg Oncol 17:1406-1413, 2010

10. Bueno-de-Mesquita JM, van Harten WH, Retel VP, et al: Use of 70-gene signature to predict prognosis of patients with node-negative breast cancer: A prospective community-based feasibility study (RASTER). Lancet Oncol 8:1079-1087, 2007

11. Drukker CA, Bueno-de-Mesquita JM, Retèl VP, et al: A prospective evaluation of a breast cancer prognosis signature in the observational RASTER study. Int J Cancer 133:929-936, 2013

12. Cardoso F, van't Veer LJ, Bogaerts J, et al: 70gene signature as an aid to treatment decisions in early-stage breast cancer. N Engl J Med 375: 717-729, 2016

13. Kwaliteitsinstituut voor de gezondheidszorg CBO VVIK. Risicoprofilering. Richtlijn mammacarcinoom 81-83, 2012

14. Senkus E, Kyriakides S, Penault-Llorca F, et al: Primary breast cancer: ESMO clinical practice guidelines for diagnosis, treatment and follow-up. Ann Oncol 24:vi7-vi23, 2013 (suppl 6)

15. Kuijer $A$, van Bommel $A C$, Drukker $C A$, et al: Using a gene expression signature when controversy exists regarding the indication for adjuvant systemic treatment reduces the proportion of patients receiving adjuvant chemotherapy: A nationwide study. Genet Med 18:720-726, 2016

16. Kuijer A, Drukker CA, Smorenburg $C$, et al. Change over time in the impact of gene-expression profiles on the administration of adjuvant $\mathrm{CT}$. Int $J$ Cancer 139:769-775, 2016

17. Wishart GC, Bajdik CD, Dicks E, et al: PREDICT Plus: Development and validation of a prognostic model for early breast cancer that includes HER2. Br J Cancer 107:800-807, 2012

18. Drukker CA, Nijenhuis MV, Bueno-deMesquita JM, et al: Optimized outcome prediction in breast cancer by combining the 70-gene signature with clinical risk prediction algorithms. Breast Cancer Res Treat 145:697-705, 2014

19. Marshall DA, Deal $K$, Bombard $Y$, et al: How do women trade-off benefits and risks in chemotherapy treatment decisions based on gene expression profiling for early-stage breast cancer? A discrete choice experiment. BMJ Open 6:e010981, 2016

20. DeFrank JT, Carey LA, Brewer NT: Understanding how breast cancer patients use risk information from genomic tests. J Behav Med 36: 567-573, 2013

21. Exner $R$, Bago-Horvath $Z$, Bartsch $R$, et al: The multigene signature MammaPrint impacts on multidisciplinary team decisions in $\mathrm{ER}+$,
HER2 - early breast cancer. Br J Cancer 111 837-842, 2014

22. Cusumano PG, Generali D, Ciruelos $E$, et al: European inter-institutional impact study of MammaPrint. Breast 23:423-428, 2014

23. Torrisi R, Garcia-Etienne CA, Losurdo A, et al: Potential impact of the 70-gene signature in the choice of adjuvant systemic treatment for ER positive, HER2 negative tumors: A single-institution experience. Breast 22:419-424, 2013

24. Carlson JJ, Roth JA: The impact of the Oncotype Dx breast cancer assay in clinical practice: A systematic review and meta-analysis. Breast Cancer Res Treat 141:13-22, 2013

25. Martín M, González-Rivera M, Morales S, et al: Prospective study of the impact of the Prosigna assay on adjuvant clinical decision-making in unselected patients with estrogen receptor positive, human epidermal growth factor receptor negative, node negative early-stage breast cancer. Curr Med Res Opin 31:1129-1137, 2015

26. Wuerstlein $R$, Sotlar $K$, Gluz $O$, et al: The West German Study Group breast cancer intrinsic subtype study: A prospective multicenter decision impact study utilizing the Prosigna assay for adjuvant treatment decision-making in estrogenreceptor-positive, HER2-negative early-stage breast cancer. Curr Med Res Opin 32:1217-1224, 2016

27. Levine MN, Julian JA, Bedard PL, et al: Prospective evaluation of the 21-gene recurrence score assay for breast cancer decision-making in Ontario. $\mathrm{J}$ Clin Oncol 34:1065-1071, 2016

\section{Affiliations}

Anne Kuijer, Marieke Straver, Bianca den Dekker, Annelotte C.M. van Bommel, and Thijs van Dalen, Diakonessenhuis; Anne Kuijer, Sjoerd G. Elias, Sabine C. Linn, and Thijs van Dalen, University Medical Centre Utrecht; Sabine Siesling, Netherlands Comprehensive Cancer Organization, Utrecht; Carolien H. Smorenburg and Jelle Wesseling, Antoni van Leeuwenhoek Hospital; Carolien H. Smorenburg, Jelle Wesseling, Sabine C. Linn, and Emiel J.Th. Rutgers, Netherlands Cancer Institute, Amsterdam; and Sabine Siesling, University of Twente, Enschede, the Netherlands.

\section{Support}

Supported by an unrestricted research grant from Agendia NV.

\section{Prior Presentation}

Previously presented in part at the Society of Surgical Oncology Symposium Boston, MA, March 2-5, 2016, and at the 10th European Breast Cancer Congress, Amsterdam, the Netherlands, March 9-11, 2016. 


\section{AUTHORS' DISCLOSURES OF POTENTIAL CONFLICTS OF INTEREST}

Impact of 70-Gene Signature Use on Adjuvant Chemotherapy Decisions in Patients With Estrogen Receptor-Positive Early Breast Cancer: Results of a Prospective Cohort Study

The following represents disclosure information provided by authors of this manuscript. All relationships are considered compensated. Relationships are self-held unless noted. I = Immediate Family Member, Inst = My Institution. Relationships may not relate to the subject matter of this manuscript. For more information about ASCO's conflict of interest policy, please refer to www.asco.org/rwc or ascopubs.org/jco/site/ifc.

\section{Anne Kuijer}

No relationship to disclose

\section{Marieke Straver}

No relationship to disclose

\section{Bianca den Dekker}

No relationship to disclose

Annelotte C.M. van Bommel

No relationship to disclose

Sjoerd G. Elias

No relationship to disclose

Carolien H. Smorenburg

No relationship to disclose

Jelle Wesseling

No relationship to disclose

\section{Sabine C. Linn}

Consulting or Advisory Role: AstraZeneca (Inst), IBM (Inst) Research Funding: Roche/Genentech (Inst), AstraZeneca (Inst), Bristol-Myers Squibb (Inst)

Patents, Royalties, Other Intellectual Property: Patent holder, BRCAness gene signature (Inst)

Travel, Accommodations, Expenses: Roche, Pfizer

\section{Emiel J.Th. Rutgers}

No relationship to disclose

\section{Sabine Siesling}

No relationship to disclose

Thijs van Dalen

No relationship to disclose 


\section{Acknowledgment}

We thank all patients for participation in this study and Marianne Deelen for her logistic support in performance of this study. We also thank all of the principal investigators and the participating hospitals for their collaboration: A. Imholz (Deventer Ziekenhuis, Deventer), A. Honkoop (Isala Ziekenhuis, Zwolle), A. Timmer-Bonte (Alexander Monro, Bilthoven), P. Nieboer (Wilhelmina Ziekenhuis, Assen), S. Hovenga (Ziekenhuis Nij Smellighe, Dronten), J. Hunting (Antoniusziekenhuis, Nieuwegein), T. Smilde (Jeroen Bosch Ziekenhuis, Den Bosch), E. Vriens (Ter Gooi Ziekenhuis, Hilversum), H. Zuetenhorst (St. Fransiscus Gasthuis, Rotterdam), A. van der Velden (Martini Ziekenhuis, Groningen), B. de Valk (Spaarne Ziekenhuis, Hoofddorp), B. Spaansen (Gemini Ziekenhuis, Den Helder), Q. van Rossum (Vlietland Ziekenhuis, Sliedrecht), M.W.A. van Tilburg (Sint Jansdal, Harderwijk), A. van der Pas (Lange Land Ziekenhuis, Zoetermeer), A. Haringhuizen (Ziekenhuis Gelderse Vallei, Ede), W. Lastdrager (Gelre Ziekenhuis, Apeldoorn), C. Blanken (Rijnstate Ziekenhuis, Arnhem), H. Rijna (Kennemer Gasthuis, Haarlem), R. van Doorn (Zuwe Hofpoort Ziekenhuis, Woerden), J. de Boer (Tjongerschans, Heereveen), S. Vrijaldenhoven (Medisch Centrum Alkmaar), J. Bollen (Medisch Centrum Zuiderzee, Lelystad), L. de Widt (Waterland Ziekenhuis, Purmerend), M. de Roos (Ziekenhuis Rivierenland, Tiel), G. Tetteroo (IJsselland ziekenhuis, Capelle aan de IJssel), C. van Riel (Antoniusziekenhuis, Sneek), S.Muller (ZaansMedisch Centrum), S. Dohmen (Boven IJ Ziekenhuis, Amsterdam), J. deWaard (West Fries Gasthuis, Hoorn), M. Jagers op Akkerhuis (Ropke Zweers, Hardenberg), J. Ketel (Gelre Ziekenhuis, Zutphen), and Meerum Terwogt (Onze Lieve Vrouwe Gasthuis, Amsterdam). 